\title{
The Itch-Producing Agents Histamine and Cowhage Activate Separate Populations of Primate Spinothalamic Tract Neurons
}

\author{
Steve Davidson, ${ }^{1,3}$ Xijing Zhang, ${ }^{1}$ Chul H. Yoon, ${ }^{1}$ Sergey G. Khasabov, ${ }^{2}$ Donald A. Simone, ${ }^{2,3}$ and Glenn J. Giesler Jr ${ }^{1,3}$ \\ ${ }^{1}$ Department of Neuroscience, Medical School, ${ }^{2}$ Department of Diagnostic and Biological Sciences, School of Dentistry, and ${ }^{3}$ Graduate Program in \\ Neuroscience, University of Minnesota, Minneapolis, Minnesota 55455
}

Itch is an everyday sensation, but when associated with disease or infection it can be chronic and debilitating. Several forms of itch can be blocked using antihistamines, but others cannot and these constitute an important clinical problem. Little information is available on the mechanisms underlying itch that is produced by nonhistaminergic mechanisms. We examined the responses of spinothalamic tract neurons to histaminergic and, for the first time, nonhistaminergic forms of itch stimuli. Fifty-seven primate spinothalamic tract (STT) neurons were identified using antidromic activation techniques and examined for their responses to histamine and cowhage, the nonhistaminergic itch-producing spicules covering the pod of the legume Mucuna pruriens. Each examined neuron had a receptive field on the hairy skin of the hindlimb and responded to noxious mechanical stimulation. STT neurons were tested with both pruritogens applied in a random order and we found 12 that responded to histamine and seven to cowhage. Each pruritogen-responsive STT neuron was activated by the chemical algogen capsaicin and two-thirds responded to noxious heat stimuli, demonstrating that these neurons convey chemical, thermal, and mechanical nociceptive information as well. Histamine or cowhage responsive STT neurons were found in both the marginal zone and the deep dorsal horn and were classified as high threshold and wide dynamic range. Unexpectedly, histamine and cowhage never activated the same cell. Our results demonstrate that the spinothalamic tract contains mutually exclusive populations of neurons responsive to histamine or the nonhistaminergic itch-producing agent cowhage.

Key words: pruritus; spinal cord; electrophysiology; pain; capsaicin; dorsal horn

\section{Introduction}

Itch and scratching perform an important function in protecting the skin from common threats, but itch can become intolerable and lead to vicious itch-scratch cycles and self injury (Keele and Armstrong, 1964; Wahlgren, 1999; Oaklander et al., 2002). Pruritus often accompanies skin and systemic diseases, and can be a symptom of neuropathy (Yosipovitch et al., 2003; Ikoma et al., 2006). Several types of itch are produced by histaminergic mechanisms and pruritus is commonly treated with antihistamines. Moreover, intracutaneous application of histamine produces dose-dependent itch and a flare response (Simone et al., 1987, 1991; Magerl et al., 1990). However, antihistamines often fail to block clinically significant pruritus (Klein and Clark, 1999; Wahlgren, 1999), and itch can be induced by electrical stimulation without the flare that follows the release of histamine into the skin (Ikoma et al., 2005). These findings indicate that itch can also be produced through nonhistaminergic mechanisms (Steinhoff et al., 2003, 2006).

Received June 22, 2007; revised Aug. 2, 2007; accepted Aug. 2, 2007

This work was supported by National Institutes of Health Grants NS047399 and NS059199. We thank Hai Truong for his expert technical assistance and Edward G. Jones for his help with the identification of thalamic structures.

Correspondence should be addressed to Glenn J. Giesler Jr, Department of Neuroscience, 6-145 Jackson Hall, University of Minnesota, Minneapolis, MN 55455. E-mail: giesler@umn.edu.

DOI:10.1523/JNEUROSCI.2862-07.2007

Copyright $\odot 2007$ Society for Neuroscience $\quad 0270-6474 / 07 / 2710007-08 \$ 15.00 / 0$
Cowhage (which consists of trichomes covering the pod of the tropical legume Mucuna pruriens) has long been used in the production of experimental itch. A single trichome can produce an intense itch lasting several minutes that begins shortly after insertion into the skin (Graham et al., 1951; Shelley and Arthur, 1957; Tuckett, 1982). An early biochemical study by Shelley and Arthur, (1955) indicated that cowhage spicules contain an itchproducing proteinase they named mucunain. Applications of cowhage produce little, if any, flare and an itch that cannot be blocked with antihistamines (Graham et al., 1951; Johanek et al., 2007). In this study, cowhage was used as a model of nonhistaminergic itch.

The spinothalamic tract (STT) is thought to play an important role in conveying ascending information related to itch. In support of this idea, anterolateral cordotomy eliminates the perception of itch produced by poison ivy, histamine, and cowhage from within the analgesic zones (Bickford, 1938; Hyndman and Wolkin, 1943; White and Sweet, 1969). Also, a subset of axons recorded from the ventrolateral funiculus of cats was found to be responsive to cowhage applied within their cutaneous receptive fields (Wei and Tuckett, 1991). More recently, histamine-sensitive neurons in the marginal zone that were antidromically activated from the thalamus were discovered in cats (Andrew and Craig, 2001). These histamine-sensitive STT neurons did not respond to mechan- 


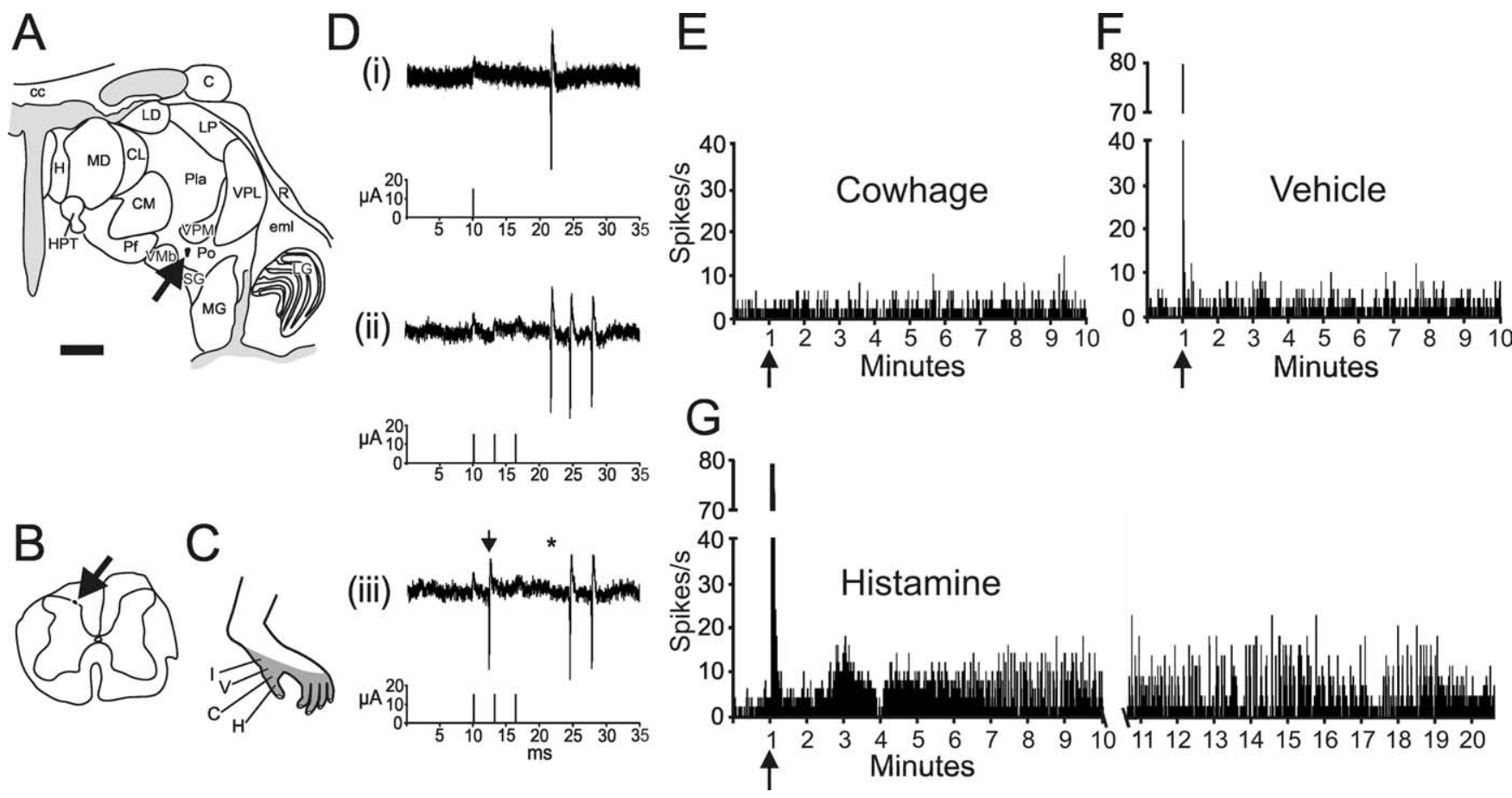

Figure 1. Antidromic activation of a histamine-responsive STT neuron. A, Location of the lesion at the stimulating point in the posterior nucleus. Scale bar, $2.0 \mathrm{~mm}$. C, Caudate; $c$, corpus callosum; $\mathrm{CL}$, center lateral nucleus (n.); $\mathrm{CM}$, center median n.; eml, external medullary lamina; $\mathrm{H}$, habenula; HPT, habenulopeduncular tract; LD, lateral dorsal $\mathrm{n}$;; $\mathrm{LG}$, lateral geniculate n.; $\mathrm{LP}$, lateral posterior n.; MD, mediodorsal n.; MG, medial geniculate n.; Pf, parafascicular n.; Pla, anterior pulvinar; Pli, inferior pulvinar; Pll, lateral pulvinar; PIm, medial pulvinar; Po, posterior n; R, reticular n; SG, suprageniculate n.;VMb, ventrobasal part of the ventral medial n.;VPI, ventral posterior inferior n.;VPM, ventral posterior medial $n$. $\boldsymbol{B}$, Location of the recording point in the marginal zone of lumbar spinal cord (arrow). C, Receptive field. Letters indicate the location of each stimulus. H, Histamine; $V$, vehicle; $C$, cowhage; I, inactive cowhage. D, Five overlaid traces demonstrate the constant latency of $11.6 \mathrm{~ms}$ from the stimulation $(15 \mu \mathrm{A})$ to recording (i). The neuron followed a $>300 \mathrm{~Hz}$ train without failure (ii), and an ascending orthodromic action potential (iii, arrow) collided with an antidromic action potential (asterisk located at the anticipated latency). $\boldsymbol{E}, \boldsymbol{F}$, Stimuli were applied in the order illustrated. This neuron was not excited by cowhage or vehicle applied to the receptive field by a cotton tipped swab. Bin width for this and all single unit histograms is 1 s. G, The response to histamine lasted 20 min.

ical stimulation or mustard oil, suggesting that they constituted a selective central pathway for itch. However, because these units were not tested for a response to the painful chemical capsaicin, their inability to also process pain information remains uncertain (Schmelz et al., 1997, 2003).

In primates, wide dynamic range (WDR) neurons antidromically activated from the ventral posterior lateral (VPL) nucleus of the thalamus responded to histamine and also to capsaicin, challenging the idea of an itch specific STT pathway (Simone et al., 2004). Here, we examined whether primate STT neurons with projections to somatosensory thalamus responded to histamine and cowhage. Both pruritogens were sequentially applied to the receptive fields of high-threshold (HT) and WDR STT neurons located in the deep and superficial dorsal horn. We found that some cells responded to histamine and others to cowhage but, surprisingly, none responded to both. Our results suggest that dual, independent central pathways exist for itch.

\section{Materials and Methods}

Surgical preparation. Macaques (Macaca fascicularis or mulatta) of either sex were used in accordance with protocols approved by the Animal Care Committee of the University of Minnesota. Each animal was initially sedated with ketamine $(10 \mathrm{mg} / \mathrm{kg}$, i.m. $)$, and an intravenous catheter was placed in the forelimb. Sodium pentobarbital $(20 \mathrm{mg} / \mathrm{ml}$, i.v.) was given to produce a depth of anesthesia suitable for surgery. A tracheotomy was performed and the brachial artery catheterized to monitor blood pressure and heart rate. Alpha chloralose $(60 \mathrm{mg} / \mathrm{kg}$, i.v.) was delivered and the monkeys were fixed to a stereotaxic frame. Body temperature was monitored and maintained at $37.5^{\circ} \mathrm{C}$ with a feedback-controlled heating blanket. Monkeys were paralyzed with gallamine triethiodide and artifi- cially ventilated. End tidal $\mathrm{CO}_{2}$ was monitored continuously and maintained between 3.6 and $4.2 \%$. A mixture of sodium pentobarbital (20\%), gallamine triethiodide (30\%), and $0.9 \%$ saline $(50 \%)$ was infused continuously (i.v., $2-7 \mathrm{mg} / \mathrm{kg} / \mathrm{h}$ of sodium pentobarbital to maintain a sufficient level of anesthesia). Experiments were ceased and the animals killed by overdose of pentobarbital when blood pressure dropped below $65 \mathrm{mmHg}$.

The lumbosacral enlargement was exposed by laminectomy and a bilateral craniotomy over the thalami was performed to allow electrodes through the cortex and into the thalamus. The dura was retracted from the brain and spinal cord. The spinal cord was bathed in warm mineral oil and the cortex was bathed in a mixture of petroleum jelly and mineral oil. Bilateral pneumothoraces were performed when required to stabilize the spinal cord from movement caused by respiration.

Identification of spinothalamic tract neurons. Spinothalamic tract neurons were identified by antidromic stimulation from the thalamus (Zhang et al., 1999). First, the somatotopic organization of VPL was determined by recording multiunit activity during gentle mechanical stimulation of the contralateral body surface. Then, a stainless-steel monopolar stimulating electrode was positioned within the distal hindlimb region in the caudal third of VPL and a second stimulating electrode was placed $2 \mathrm{~mm}$ caudal and $2 \mathrm{~mm}$ medial relative to the VPL electrode within the posterior thalamus. We used this arrangement because many axons of the STT terminate within or pass through the posterior thalamus. Using two electrodes for a search stimulus allowed a broader area for current to spread and could therefore activate a greater number of STT axons. This reduced the possibility of omitting STT neurons from our sample that did not have axonal projections to VPL. A search stimulus was generated simultaneously at each stimulating electrode (cathode, $500 \mu \mathrm{A}, 200 \mu \mathrm{s}, 5 \mathrm{~Hz}$ ).

Single STT neurons were located by repeatedly lowering a 5-10 $\mathrm{M} \Omega$ steel microelectrode within the dorsal horn until antidromic action po- 
A
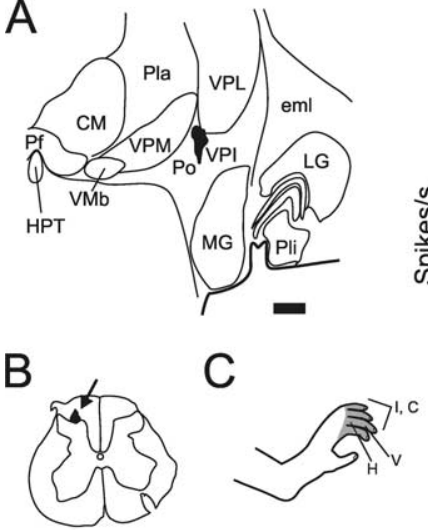

F
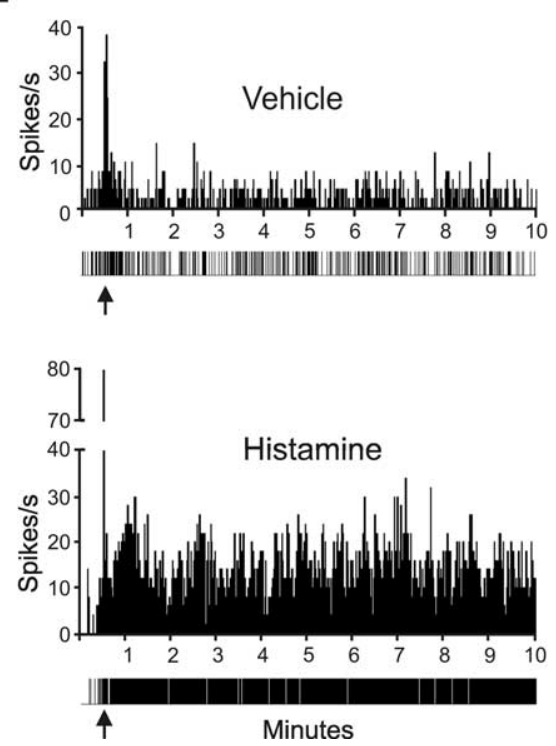

$E$

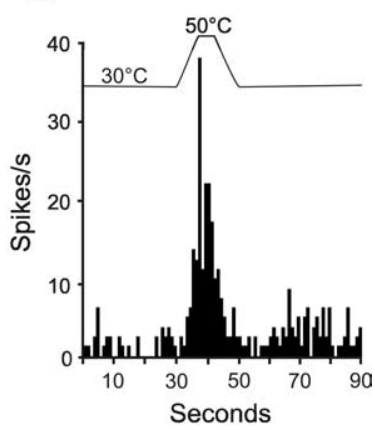

G
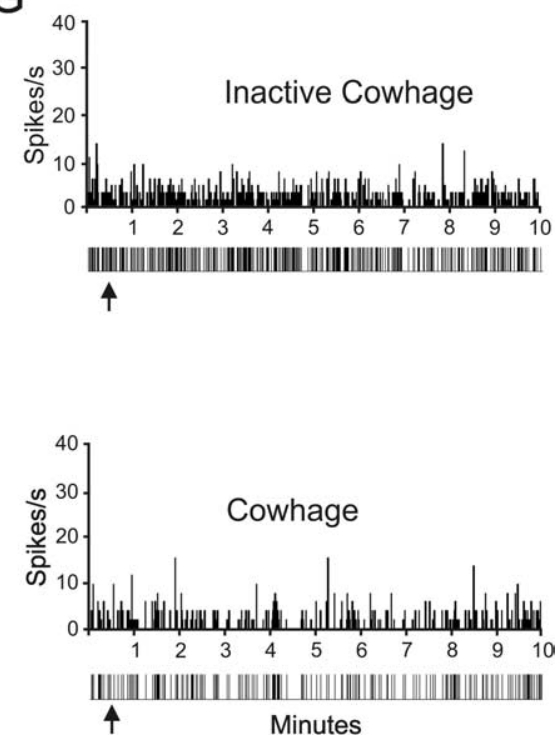

Figure 2. Example of a HT histamine responsive spinothalamic tract neuron. $\boldsymbol{A}$, Location of the lesion marking the stimulating point in the ventral posterior inferior nucleus of the thalamus. The axon was antidromically activated with $27 \mu \mathrm{A}$. Scale bar, 1.0 $\mathrm{mm}$. $\boldsymbol{B}$, Lesion at the recording point in the marginal zone. $\boldsymbol{C}$, The receptive field extended over the hairy skin of four toes. $\boldsymbol{D}$, Histogram of responses during brush (B), pressure (Pr), pinch (Pi), and squeeze $(S)$ of the receptive field. $\boldsymbol{E}$, Response of this neuron to a heat ramp to $50^{\circ} \mathrm{C}$. $\boldsymbol{F}$, Vehicle (top) and histamine (bottom) were injected intradermally (arrows). Impulse record is shown below the histogram. G, Inactive cowhage (top) and cowhage (bottom) were applied (arrows) to the skin via an M. pruriens pod. See Figure 1 legend for abbreviations.

tentials could be recorded. STT units were identified by an ability to generate an action potential at a constant latency from the stimulus, follow a $\geq 300 \mathrm{~Hz}$ stimulus train, and demonstrate collision between an antidromic action potential and an orthodromic action potential (Lipski, 1981). Once an STT unit was identified, the stimulating electrode was systematically repositioned in the thalamus until the axon could be antidromically activated with $<30 \mu \mathrm{A}$. This amount of current has been shown to activate axons $\leq 400 \mu \mathrm{m}$ from the stimulating electrode (Burstein et al., 1991; Dado et al., 1994). Action potentials were amplified, filtered, and converted to a digital signal to be displayed on custom software and analyzed off-line. The average conduction velocity along each axon was determined as described by Zhang et al. (1999).

Stimulus application and unit classification. The receptive field of each neuron was mapped using minimally noxious mechanical stimuli. Units were classified as WDR if responsive to brushing and pinching, or HT if responsive to pinching only. Brushing was done with a handheld softbristled brush; pressure was applied with a large arterial clip, pinch with a painful, small arterial clip, and squeeze, when necessary because of a lack of response to less intense stimuli, was done with forceps.

Histamine dihydrochloride ( $20 \mu \mathrm{g}$ in $10 \mu \mathrm{l} 0.9 \%$ saline), $\mathrm{pH} 5.0$, or a $\mathrm{pH}$-matched vehicle was delivered intradermally through a 28 -gauge needle (Simone et al., 2004). In the initial experiments, cowhage was applied by pressing the entire pod onto the receptive field, leaving 50-100 trichomes inserted in the skin. Later, cowhage was plucked from the pod and inserted into a cotton-tipped swab so that each trichome pointed out. Approximately 20 trichomes were applied by pressing the swab against the skin. Cowhage was rendered inactive by placing the pod in an autoclave for $20 \mathrm{~min}$. Inactive cowhage was applied in the same manner in which active cowhage was applied. Autoclaved (inactive) cowhage did not produce itch the experimenters, but the structural integrity of the trichomes was maintained.

Every cell received each of the four treatments; the vehicle always preceded histamine and the inactive form always preceded the active form of cowhage. Four equidistant point were marked within the mechanically identified receptive field and each control or pruritogen application occurred near one of these points. Thus, stimuli were applied to skin that was free of a bleb or wheal caused by injection. The order of presentation of histamine and cowhage was randomized to test for possible cross-tachyphylaxis or sensitization. Trichomes from active and inactive cowhage were removed from the skin after the test with a piece of low-tack paper tape (TimeMed Labeling Systems, Burr Ridge, IL). A minimum of 20 min was taken between stimulus applications. STT neurons were considered responsive to an itchproducing agent when the rate of action potentials ( 1 ) increased $\geq 1.5$ times the mean baseline frequency calculated during 30 or $60 \mathrm{simmedi}$ ately before the application, and (2) outlasted any response to the control stimulus by $\geq 60 \mathrm{~s}$. A heat stimulus (ramped to $50^{\circ} \mathrm{C}$; maintained for $5 \mathrm{~s}$ ) was delivered with a peltier-type stimulator (contact area of $9 \times 9 \mathrm{~mm}$ ). The stimulated surface of the skin was maintained at $30^{\circ} \mathrm{C}$ for at least $60 \mathrm{~s}$ before the stimulus. A response was defined as a change in the frequency of action potentials of $\geq 1.5$ compared with the mean firing rate during the $30 \mathrm{~s}$ immediately before the heat ramp. At the end of testing for responses to itch-producing agents, $10 \mu \mathrm{g}$ of capsaicin in $10 \mu \mathrm{l}$ of $7 \%$ Tween 80 in normal saline was injected intradermally.

Identification of stimulating and recording sites. At the end of the experiment, a lesion $(25 \mu \mathrm{A}, 40 \mathrm{~s})$ was made at the stimulation point in the thalamus at which the smallest current was required to antidromically activate the axon $(\leq 30 \mu \mathrm{A})$. A lesion was also made $(25 \mu \mathrm{A}, 15 \mathrm{~s})$ at the recording site. Monkeys were perfused with $0.9 \%$ saline and $10 \%$ formalin with $1 \%$ potassium ferrocyanide. Tissue was stored at $4^{\circ} \mathrm{C}$ in $10 \%$ formalin for several days. Brains were blocked and cut on a freezing microtome in $50 \mu \mathrm{m}$ serial coronal sections. Spinal cords were cut in the transverse plane. The tissue was stained with neutral red and lesions were identified by the Prussian blue reaction. Thalamic nuclei were identified according to Jones (2006).

Data analysis. The Fischer exact test was used to compare nonparametric categorical statistics with a value of $p<0.05$ considered significant. Single units were assessed in $1 \mathrm{~s}$ bins. For averaged data, the number of action potentials was assessed in $15 \mathrm{~s}$ bins. To reduce the effects of cell-to-cell firing-rate variability, each cell was normalized to its firing rate (per $15 \mathrm{~s}$ bin) during the histamine injection. The normalized responses were averaged and plotted with SE. Average conduction velocities were compared with the Student's $t$ test and a value of $p<0.05$ was taken to be significant. 


\section{Results}

General characteristics

Fifty-seven dorsal horn STT neurons were tested for responses to both histamine and cowhage. Nineteen (32\%) STT neurons responded to one pruritogen or the other; no cell responded to both histamine and cowhage. The exclusive response to histamine or cowhage occurred regardless of the order of application. Males and females had similar proportions of STT neurons that responded to histamine or cowhage (Fisher's exact test, $p=0.14$ ). Fifty-eight percent (18 of 31) of STT neurons that did not respond to a pruritogen were excited by a $50^{\circ} \mathrm{C}$ stimulus. This ratio was similar for cowhage responsive (4 of 6 ) or histamine responsive (8 of 12) STT neurons. After testing STT neurons for responses to itch-producing agents, the receptive field of each pruritogen responsive neuron was injected with $10 \mu \mathrm{g}$ capsaicin. Every pruritogen responsive unit also responded to capsaicin ( $\mathrm{Si}$ mone et al., 2004).

\section{Histamine-responsive STT neurons}

Figure 1 illustrates an example of an antidromically identified STT neuron activated by histamine. Small current pulses of 15 $\mu \mathrm{A}$ from a stimulating electrode placed in the posterior nucleus of the thalamus (Fig. $1 A$ ) elicited action potentials that were recorded in the superficial dorsal horn (Fig. $1 B$ ). Action potentials had a constant latency (Fig. $1 \mathrm{Di}$ ), followed a $>300 \mathrm{~Hz}$ train (Fig. 1 Dii), and demonstrated collision between an orthodromic action potential and the antidromic action potential (Fig. 1 Diii). This neuron was classified WDR; it responded to innocuous and noxious mechanical stimuli within its receptive field (Fig. 1C) (data not shown). Inactive cowhage and cowhage were applied first and then vehicle and histamine. There was no response to cowhage or vehicle (Fig. $1 E, F$ ), but $\sim 20 \mathrm{~min}$ of activity was produced by an injection of histamine (Fig. $1 G$ ). This duration of activity is consistent with psychophysical reports of the duration of itch from $20 \mu \mathrm{g}$ of histamine (Simone et al., 1991).

An example of an HT STT neuron is illustrated (Fig. 2). The axon was antidromically activated from the ventral posterior inferior nucleus (Fig. 2A). Antidromic action potentials were recorded from the marginal zone (Fig. $2 B$ ). The receptive field extended over the appendages of the hindfoot (Fig. 2C). This neuron responded to squeezing the skin with forceps, but not to brushing, pressure, or pinching within its receptive field (Fig. $2 D)$. Figure $2 E$ illustrates the response of this STT neuron to a noxious heat stimulus. The discharge produced during the injection of histamine was greater than the discharge during the injection of vehicle as shown in Figure $2 F$. The level of activity remained greater than that of the vehicle for $\geq 10 \mathrm{~min}$ after the histamine injection (Fig. $2 F$ ). The histamine-responsive unit was later tested for a response to inactive and active cowhage, but neither produced a discharge even when an area of $>5.0 \mathrm{~cm}^{2}$ in the center of the receptive field was covered with trichomes by direct application of the entire pod (Fig. $2 G$ ).

Twelve STT neurons (21\%) responded to histamine and the mean responses of these neurons normalized to their individual peak discharge during the histamine injection are presented in Figure 3. Eight of the 12 neurons continuously responded for between 5 and $25 \mathrm{~min}$. Four neurons responded for $>90 \mathrm{~s}$ and $<5$ min. Histamine produced a higher peak discharge than the vehicle and neurons maintained a higher firing rate over the course of the recording period (Fig. $3 A$ ). The vehicle produced an initial discharge during the injection, but the firing rate quickly returned to baseline. Figure $3 B$ illustrates the activity
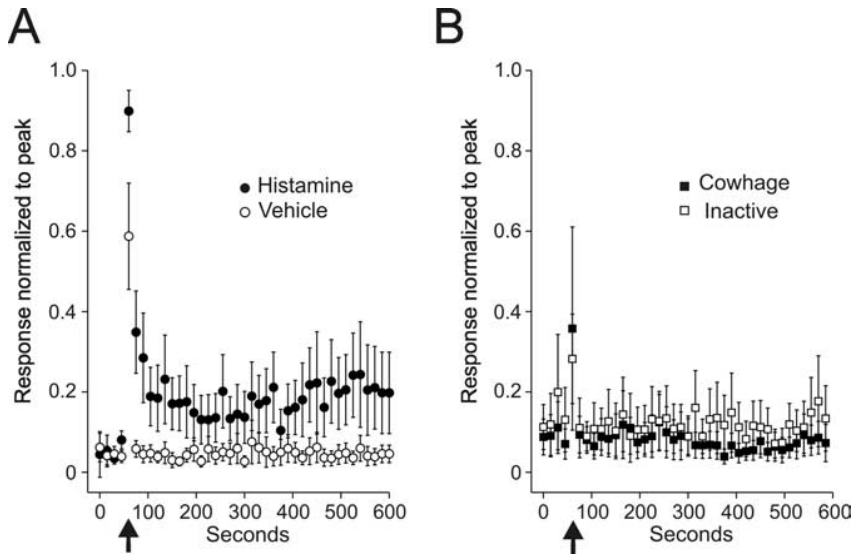

Figure 3. Mean \pm SEM of 12 histamine responsive STT units normalized to the peak discharge during intradermal histamine injection. Data points are the mean of consecutive $15 \mathrm{~s}$ bins. $\boldsymbol{A}$, Response to histamine and vehicle. Arrows indicate the time of injection. In some cells, the largest number of action potentials per $15 \mathrm{~s}$ bin came after the injection; therefore, the normalized peak did not equal 1.0. $\boldsymbol{B}$, Response of the same cells in $\boldsymbol{A}$ to inactive and active cowhage.

levels when these same neurons were tested with inactive cowhage and cowhage. No responses were observed.

\section{Cowhage-responsive STT neurons}

Seven cowhage-responsive units were recorded. An example of one cowhage-responsive STT neuron is shown in Figure 4. The stimulating site was located along the border of the posterior nucleus and the dorsal part of the medial geniculate nucleus (Fig. $4 A$ ). The recording site was located in the superficial dorsal horn (Fig. $4 B$ ). The receptive field was located on the hairy skin of the medial part of the hindfoot (Fig. 4C). This neuron was classified WDR (Fig. 4D). Vehicle and histamine produced a brief discharge during the intradermal injection, but no lasting response occurred over baseline activity (Fig. $4 E$ ). Inactive cowhage did not produce a discharge, but active cowhage produced a brief peak response at the time of the application, a short period of quiescence, and a response lasting several minutes (Fig. 4F). A short period of quiescence after the application of cowhage was observed in four of seven cowhage-responsive neurons (Fig. 5).

Figure 5 illustrates one of two cowhage-responsive neurons on which we tried repeated cowhage applications; both neurons responded similarly. The axon was stimulated from the suprageniculate nucleus (Fig. 5A) and the cell was recorded from the deep dorsal horn (Fig. 5B). The receptive field extended over the entire hindfoot (Fig. 5C). Vehicle and histamine injections did not produce a response (Fig. 5D), nor did application of inactive cowhage to the receptive field (Fig. $5 E$ ). In contrast, cowhage produced an initial peak response followed by a period of quiescence and then a discharge lasting $\geq 1 \mathrm{~min}$. The cowhage was reapplied after $25 \mathrm{~min}$ and a third time 10 min later. Each additional application produced a similar discharge pattern (Fig. $5 E$ ). Figure $5 F$ illustrates the response of this neuron to intradermal injection of capsaicin.

Mean responses to cowhage and inactive cowhage are shown in Figure $6 A$. The mean duration of discharge for cowhage was $<5$ min compared with $>10$ min for a $20 \mu \mathrm{g}$ injection of histamine (Fig. 3). Inactive cowhage never produced a lasting response, although action potentials were sometimes elicited during the application. Injections of vehicle and histamine typically produced action potentials during the injection, but no lasting response (Fig. 6B). 
A
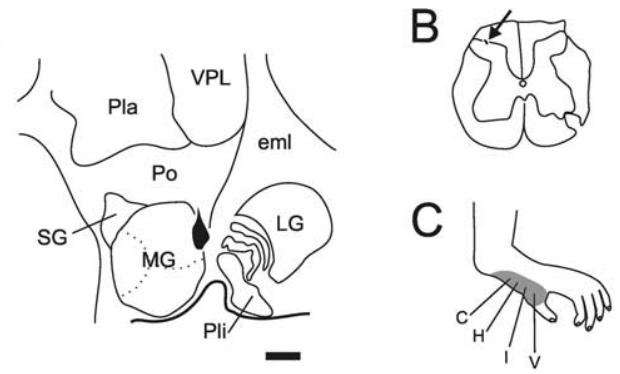

$E$
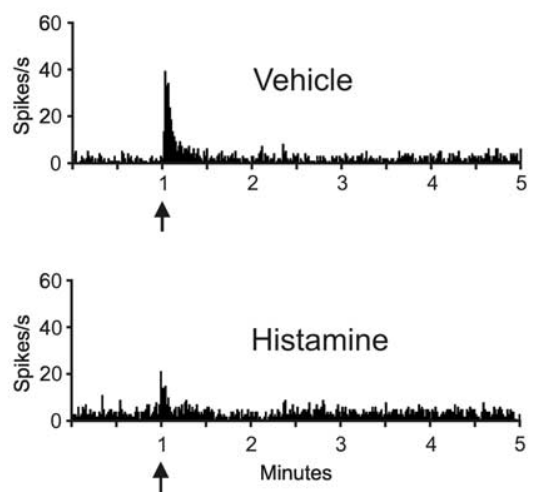

Figure 4. Example of a cowhage responsive spinothalamic tract neuron. $A$, Location of the lesion marking the stimulating point on the border of the medial geniculate nucleus and the posterior nucleus of the thalamus. The antidromic threshold was $25 \mu \mathrm{A}$. Scale bar, $1.0 \mathrm{~mm}$. B, Recording point in the marginal zone. $\boldsymbol{C}$, Receptive field over the hairy skin of hind paw. D, Histogram of responses to mechanical stimulation. This unit was classified WDR. $\boldsymbol{E}$, Vehicle and histamine produced a brief discharge during the intradermal injection. $\boldsymbol{F}$, Inactive cowhage produced no discharge, but cowhage produced a response lasting $\sim 4$ min after a latent period. See Figure 1 legend for abbreviations.

\section{Recording sites and conduction velocity}

The recording sites in the dorsal horn for histamine and cowhage-responsive STT neurons are illustrated in Figure 7. Both histamine and cowhage-responsive neurons were found in the superficial dorsal horn (Fig. $7 A, B$ ). Sixty-seven percent (12 of 18) of marginal-zone units tested were responsive to one itchproducing agent or the other. Neurons within the deep dorsal horn also responded to pruritogens, but less frequently (7 of 39 neurons; 18\%). Within the deep dorsal horn, histamineresponsive units were found in nucleus proprius and cowhageresponsive units were concentrated in the lateral reticulated area.

Pruritogen responsive HT and WDR STT neurons were recorded from both the superficial and the deep dorsal horn (Fig. $7 A, B)$. No relationship between the mechanical classification of a neuron and its ability to respond to cowhage or histamine was detected (Fisher's exact test, $p=0.37$ ). The recording sites of nociceptive STT neurons not activated by histamine or cowhage are illustrated in Figure $7 C$ for comparison. Sixteen of 23 nonpruriceptive STT neurons tested responded to capsaicin for longer than $1 \mathrm{~min}$.

The average conduction velocity of histamine-responsive STT neurons $(22.8 \mathrm{~m} / \mathrm{s} \pm 2.0 \mathrm{~m} / \mathrm{s})$ was significantly slower than the cowhage-responsive STT neurons $(33.2 \mathrm{~m} / \mathrm{s} \pm 5.1 \mathrm{~m} / \mathrm{s} ; p<0.05)$. When only the marginal-zone neurons were considered, histamine-responsive STT neurons were significantly slower than cowhage-responsive STT neurons $(22.2 \pm 3.1 \mathrm{~m} / \mathrm{s}$ vs 35.6 $\mathrm{m} / \mathrm{s} \pm 2.9 \mathrm{~m} / \mathrm{s}$, respectively; $p<0.05)$.

\section{Discussion}

The goal of this study was to determine how ascending sensory information underlying histaminergic and nonhistaminergic forms of itch is carried in primate STT neurons. Only two studies have examined the responses of STT neurons to applications of histamine (Andrew and Craig, 2001; Simone et al., 2004), and none have examined the responses of STT neurons to nonhistaminergic forms of itch. We used antidromic activation to identify primate spinothalamic tract neurons and then tested each neuron for sensitivity to histamine and cowhage. We found that $21 \%$ of examined STT neurons responded to histamine and $12 \%$ were activated by cowhage. Surprisingly, STT neurons responded either to histamine or to cowhage, but never to both, indicating that there are at least two, separate populations of STT neurons that convey pruritic information to the brain.

Most STT neurons activated by histamine responded between 5 and $25 \mathrm{~min}$. This time course reflects the expected time course of itch in humans injected with the same amount of histamine (Simone et al., 1987, 1991). Each histamine-responsive STT neuron was also activated by noxious mechanical stimuli and was classified as either HT or WDR. Sixty-seven percent of histamine-responsive neurons also responded to a noxious heat $\left(50^{\circ} \mathrm{C}\right)$ stimulus. Histamine-responsive STT neurons were located in both the marginal zone as well as in the nucleus proprius.

STT neurons responded to cowhage usually after a short latency period of 10-20 s and with a time course of several minutes. The latency and duration of the responses to cowhage parallel the sensation of itch reported in psychophysical studies (Graham et al., 1951; Shelley and Arthur, 1957; Tuckett, 1982; Johanek et al., 2007). All cowhage-responsive STT neurons were classified as HT or WDR and $67 \%$ responded to a $50^{\circ} \mathrm{C}$ heat ramp. STT neurons responsive to cowhage were located within the marginal zone and the lateral reticulated area of the dorsal horn. Cowhage could be applied repeatedly without a decrement of the response, suggesting that the pathway is not subject to tachyphylaxis. Furthermore, in about half of the pruritogen responsive STT neurons, the second pruritogen applied (cowhage or histamine) produced the response indicating that cross-tachyphylaxis between the two types of pruritogens does not occur.

Histamine-responsive neurons with unidentified axonal projections have been recorded in the rat superficial and deep dorsal horn (Carstens, 1997; Jinks and Carstens, 1998, 2000). These neurons in rats all responded to other noxious mechanical or chemical stimuli, consistent with our results of histamine (and cowhage)-responsive neurons in primate dorsal horn. However, rats do not scratch to intracutaneous injections of histamine (Jinks and Carstens, 2002); therefore, it could be concluded that the responses to histamine in rats are nociceptive rather than pruriceptive. In contrast, both histamine and cowhage elicit scratching directed to the application site in monkeys (R. H. LaMotte, personal communication). Additionally, like humans, monkeys have been shown to scratch in response to intrathecal morphine, and this scratching is not attenuated by antihistamines (Ko and Naughton, 2000; Ko et al., 2004). These data 

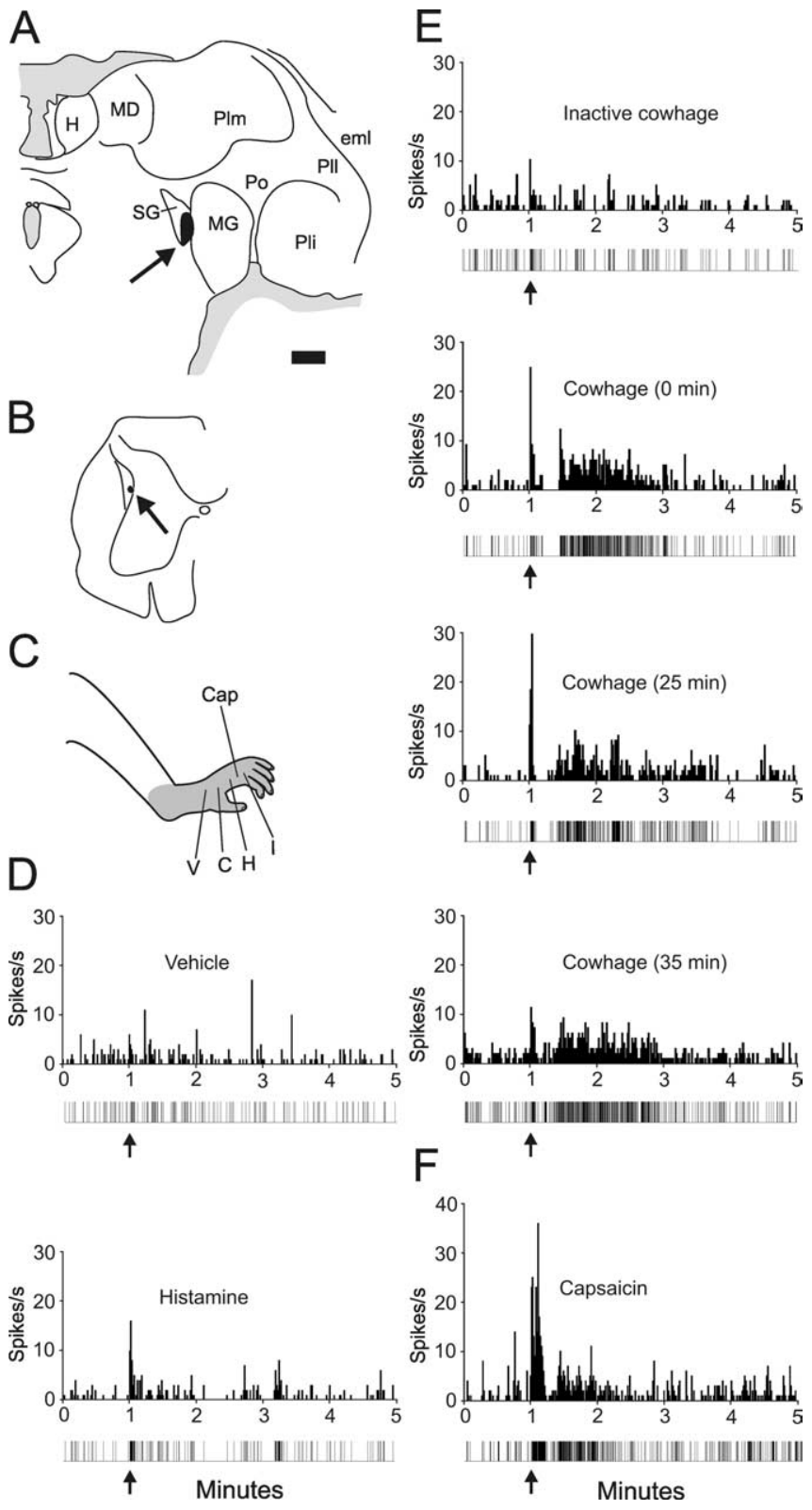

Figure 5. Example of the repeatability of the response to cowhage. $A$, Location of antidromic stimulating point $(24 \mu \mathrm{A})$ in the suprageniculate $\mathrm{n}$. of the thalamus. Scale bar, $1.0 \mathrm{~mm}$. $\boldsymbol{B}$, Recording point in the lateral reticulated area. $\boldsymbol{C}$, Receptive field over the entire hind paw. Cap, Capsaicin. $\boldsymbol{D}$, Intradermal injection of vehicle and histamine. Impulse record is shown below the histogram. $\boldsymbol{E}$, Application of inactive cowhage (top) and cowhage at three time points. $\boldsymbol{F}$, Response to $10 \mu \mathrm{g}$ of capsaicin. See Figure 1 legend for abbreviations.

support the use of monkeys as an appropriate animal model to investigate the central neural mechanisms of both histaminergic and nonhistaminergic itch.

Our data predict that STT neurons receive input from populations of primary afferent fibers that respond to histamine or cowhage, but not both. However, the current understanding of pruritic mechanisms in the periphery is incomplete. Several lines of evidence indicate that separate peripheral mechanisms exist for coding histamine- or cowhage-produced itch. As noted, cowhage produced an itch without flare and the itch was not blocked by antihistamine. In addition, desensitization of the skin with topical capsaicin prevented cowhage-induced, but not histamine-induced itch (Johanek et al., 2007). Furthermore,
A

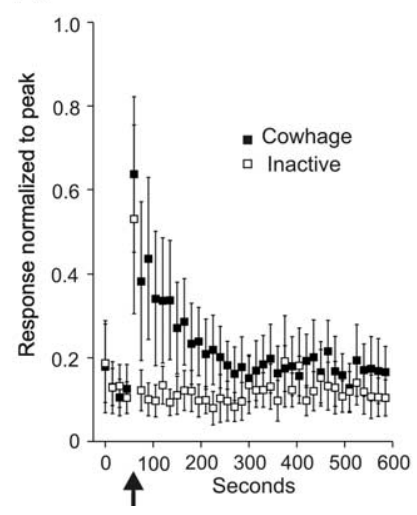

B

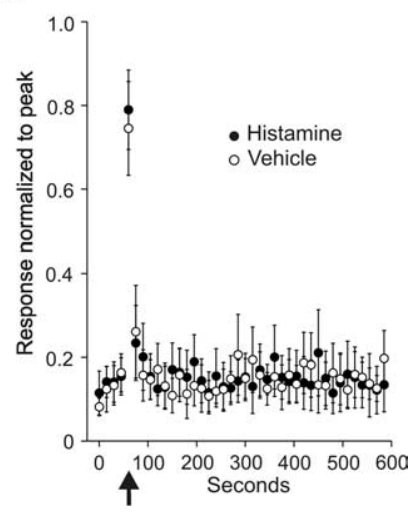

Figure 6. Mean \pm SEM of seven cowhage-responsive STT units normalized to the peak discharge during intradermal injection of histamine. $\boldsymbol{A}$, Inactive and active cowhage. $\boldsymbol{B}, \mathrm{Re}-$ sponses from the same cells to vehicle and histamine.

cowhage applied to the hairy skin of cats excited a majority of polymodal C-fibers tested (Tuckett and Wei, 1987). In contrast, histamine applied iontophoretically weakly excited only a subset of polymodal C-fibers in human (Handwerker et al., 1991; Schmelz et al., 1997). These data indicate that polymodal C-fibers encode the itch produced by cowhage. However, a previous study in monkeys demonstrated that single polymodal C-fibers can be excited by both an application of cowhage as well as an intradermal injection of histamine (Johanek et al., 2005). Thus, the role of polymodal C-fibers in encoding histamine-induced itch remains enigmatic. Additional studies are needed to determine the sources of input to the two types of pruritogen-responsive STT neurons in monkeys.

Important studies of itch have advocated the specificity theory (Schmelz et al., 1997; Andrew and Craig, 2001), which states that itch is generated by a subpopulation of neurons in the periphery and spinal cord that respond exclusively to itch-producing stimuli. The seminal observation in support for this idea came from microneurography experiments that identified a population of slowly conducting C-fibers that were mechanically insensitive and responded to histamine for a duration that matched the duration of itch sensation in humans (Schmelz et al., 1997). Because these histamine-sensitive fibers failed to respond to mechanical stimuli and also to the chemical algogen mustard oil, they were initially labeled "itch specific." However, additional examination with capsaicin and bradykinin demonstrated that these histamine-sensitive fibers also responded to painful chemicals (Schmelz et al., 2003). Moreover, the ability of many dorsal root ganglion neurons to respond to histamine has been shown previously to be contingent on the expression of the capsaicinresponsive receptor [transient receptor potential vanilloid 1 (TRPV1)], and TRPV1-null mice exhibit diminished scratching in response to histamine compared with wild-type (Shim et al., 2007) (but see Nicolson et al., 2002). Thus, even the strongest candidate primary afferent fibers for the transduction of histamine-produced itch also respond to painful chemicals. Similarly, primary afferent fibers that respond to cowhage are also all activated by noxious mechanical and heat stimuli (Tuckett and Wei, 1987; Johanek et al., 2005). These findings suggest that itch and pain are inexorably linked in the peripheral nervous system. Our results demonstrate that STT neurons responsive to histamine or cowhage can also be activated by capsaicin, noxious mechanical, and heat stimuli, indicating that the link between nox- 


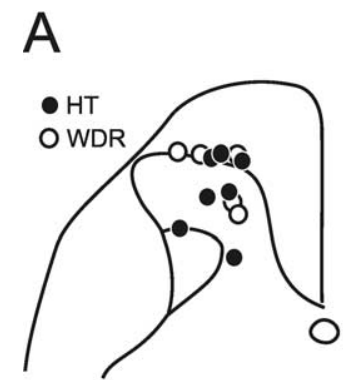

Histamine (12)

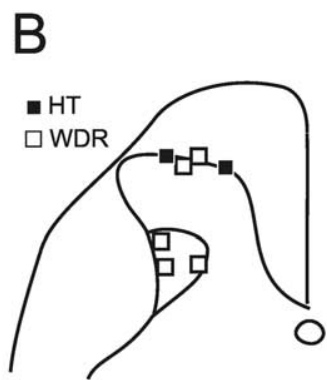

Cowhage (7)

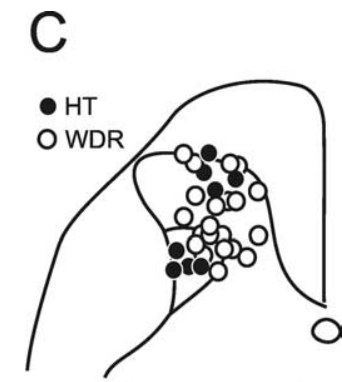

No response to pruritogen (29)

Figure 7. Location in the dorsal horn of each pruritogen responsive STT neuron with HT or WDR classification indicated. $\boldsymbol{A}_{\text {, }}$ Histamine responsive STT neurons were mostly located in the marginal zone and the nucleus proprius. Cowhage responsive units were located within the marginal zone and also within the lateral reticulated area. C, Location of the 29 recovered recording points of the 38 total STT units not excited by either histamine or cowhage.

ious and pruritic information is preserved in the responses of primate STT neurons.

Responses mirroring those of the afferent fibers thought to be itch specific were recorded from STT neurons in the marginal zone of cat (Andrew and Craig, 2001). In that study, neurons from the deep dorsal horn were not examined for responses to histamine, nor were marginal zone neurons that responded to mechanical stimuli. Our present findings indicate that mechanically sensitive STT neurons in the deep and superficial dorsal horn of primates are capable of contributing to the itch sensation. Importantly, in the study by Andrew and Craig (2001), STT neurons that responded to histamine were not tested for sensitivity to capsaicin. In our study, all primate STT neurons that responded to histamine or cowhage also responded to capsaicin. This is consistent with previous observations in primates (Simone et al., 2004). Because each pruritogen-responsive neuron responded to mechanical stimulation and to the painful chemical capsaicin, our data further complicate support for a specific itch pathway. Although a population of truly itch-specific peripheral fibers and spinal cord neurons may yet be found in primates, alternatives to the specificity theory have been considered in the past (Handwerker, 1992; McMahon and Koltzenburg, 1992; LaMotte, 1996) and deserve re-evaluation in light of the lack of evidence for a labeled-line pathway for itch. Our data are consistent with a theory of itch that recognizes that there are no primary afferent fibers that respond exclusively to pruritogens. Instead, itch is generated when a subset of central neurons is activated by inputs from primary afferent fibers responsive to both noxious and pruritic stimuli. However, pain is perceived when nociceptive-specific (i.e., not pruritic) primary afferent fibers excite additional nonpruritic spinal neurons. In primates, we found that roughly twothirds of STT neurons respond to noxious, but not to pruritic, stimuli and that about one-third respond to both pruritic and noxious stimuli. Noxious mechanical and chemical stimuli would likely activate both classes of STT neurons and produce pain. Sole activation of the STT neurons that are activated by pruritic and noxious stimuli could signal itch.

Our results indicate that separate, parallel populations of STT neurons carry ascending sensory information underlying the itch produced by histamine or cowhage. It will be valuable in future studies to determine whether other types of nonhistaminergic itch stimuli, possibly including those that more closely mirror clinical forms of itch, activate cowhage-responsive or a separate population of STT neurons. In addition, it will be interesting to determine whether processing of histaminergic and nonhista- minergic forms of itch is also performed by separate populations of neurons within higher levels of the CNS.

\section{References}

Andrew D, Craig AD (2001) Spinothalamic lamina I neurons selectively sensitive to histamine: a central neural pathway for itch. Nat Neurosci 4:72-77.

Bickford RG (1938) Experiments relating to the itch sensation, its peripheral mechanism and central pathways. Clin Sci 3:377-386.

Burstein R, Dado RJ, Cliffer KD, Giesler Jr GJ (1991) Physiological characterization of spinohypothalamic tract neurons in the lumbar enlargement of rats. J Neurophysiol 66:261-284.

Carstens E (1997) Responses of rat spinal dorsal horn neurons to intracutaneous injection of histamine, capsaicin and other irritants. J Neurophysiol 77:2499-2514.

Dado RJ, Katter JT, Giesler Jr GJ (1994) Spinothalamic and spinohypothalamic tract neurons in the cervical enlargement of rats. I. Locations of antidromically identified axons in the thalamus and hypothalamus. J Neurophysiol 71:959-980.

Graham DT, Goodell H, Wolff HG (1951) Neural mechanisms involved in itch, "itchy skin," and tickle sensations. J Clin Invest 30:37-49.

Handwerker HO (1992) Pain and allodynia, itch and alloknesis: an alternative hypothesis. Am Pain Soc J 1:135-138.

Handwerker HO, Forster C, Kirchhoff C (1991) Discharge patterns of human C-fibers induced by itching and burning stimuli. J Neurophysiol 66:307-315.

Hyndman OR, Wolkin J (1943) Anterior cordotomy: further observations on the physiologic results and optimum manner of performance. Arch Neurol Psychiatry 50:129-148.

Ikoma A, Handwerker H, Miyachi Y, Schmelz M (2005) Electrically evoked itch in humans. Pain 113:148-154.

Ikoma A, Steinhoff M, Stander S, Yosipovich G, Schmelz M (2006) The neurobiology of itch. Nat Rev Neurosci 7:535-547.

Jinks SL, Carstens E (1998) Spinal NMDA receptor involvement in the expansion of dorsal horn neuronal receptive field area produced by intracutaneous histamine. J Neurophysiol 79:1613-1618.

Jinks SL, Carstens E (2000) Superficial dorsal horn neurons identified by intracutaneous histamine: chemonociceptive responses and modulation by morphine. J Neurophysiol 84:616-627.

Jinks SL, Carstens E (2002) Responses of superficial dorsal horn neurons to intradermal serotonin and other irritants: comparison with scratching behavior. J Neurophysiol 87:1280-1289.

Johanek LM, Shim B, Meyer RA, Ringkamp M (2005) Response of C-fiber nociceptors in monkey to different pruritic stimuli. Soc Neurosci Abstr 31:511.7.

Johanek LM, Meyer RA, Hartke T, Hobelmann JG, Maine DN, LaMotte RH, Ringkamp M (2007) Psychophysical and physiological evidence for parallel afferent pathways mediating the sensation of itch. J Neurosci 27:7490-7497.

Jones EG (2007) The thalamus, Ed 2. Cambridge, UK: Cambridge UP.

Keele CA and Armstrong D (1964) Substances producing pain and itch. Baltimore: Lippincott, Williams and Wilkins.

Klein PA, Clark RA (1999) An evidence-based review of the efficacy of antihistamines in relieving pruritus in atopic dermatitis. Arch Dermatol 135:1522-1525.

Ko MC, Naughton NN (2000) An experimental itch model in monkeys: characterization of intrathecal morphine-induced scratching and antinociception. Anesthesiology 92:795-805.

Ko MC, Song MS, Edwards T, Lee H Naughton NN (2004) The role of central mu opioid receptors in opioid-induced itch in primates. J Pharmacol Exp Ther 310:169-176.

LaMotte RH (1996) Secondary cutaneous dysesthesias. In: Neurobiology of nociceptors (Belmonte C, Cervero F, eds), pp 391-417. Oxford: Oxford UP.

Lipski J (1981) Antidromic activation of neurons as an analytic tool in the study of the central nervous system. J Neurosci Methods 4:1-32. 
Magerl W, Westerman RA, Mohner B, Handwerker HO (1990) Properties of transdermal histamine iontophoresis: differential effects of season, gender, and body region. J Invest Dermatol 94:347-352.

McMahon SB, Koltzenburg M (1992) Itching for an explanation. Trends Neurosci 15:497-501.

Nicolson TA, Bevan S, Richards CD (2002) Characterization of the calcium responses to histamine in capsaicin-sensitive and capsaicin-insensitive sensory neurons. Neuroscience 110:329-338.

Oaklander AL, Cohen SP, Raju SV (2002) Intractable postherpetic itch and cutaneous deafferentation after facial shingles. Pain 96:9-12.

Schmelz M, Schmidt M, Bickel A, Handwerker HO, Torebjork HE (1997) Specific C-receptors for itch in human skin. J Neurosci 17:8003-8008.

Schmelz M, Schmidt M, Weidner C, Hilleges M, Torebjork HE, Handwerker HO (2003) Chemical response pattern of different classes of C-nociceptors to pruritogens and algogens. J Neurophysiol 89:2441-2448.

Shelley WB, Arthur RP (1955) Studies on cowhage (Mucuna pruriens) and its pruritogenic proteinase, mucunain. AMA Arch Derm 72:399-406.

Shelley WB, Arthur RP (1957) The neurohistology and neurophysiology of the itch sensation in man. Arch Dermatol 76:296-323.

Shim WS, Tak MH, Lee MH, Kim M, Kim M, Koo JY, Lee CH, Kim M, Oh U (2007) TRPV1 mediates histamine-induced itching via the activation of phospholipase A2 and 12-lipoxygenase. J Neurosci 27:2331-2337.

Simone DA, Ngeow JY, Whitehouse J, Becerra-Cabal L, Putterman GJ, LaMotte RH (1987) The magnitude and duration of itch produced by intracutaneous injections of histamine. Somatosens Mot Res 5:81-92.

Simone DA, Alreja M, LaMotte RH (1991) Psychophysical studies of the itch sensation and itchy skin ("alloknesis") produced by intracutaneous injection of histamine. Somatosens Mot Res 8:271-279.

Simone DA, Zhang X, Li J, Zhang JM, Honda CN, LaMotte RH, Giesler Jr GJ (2004) Comparison of responses of primate spinothalamic neurons to pruritic and algogenic stimuli. J Neurophysiol 91:213-222.

Steinhoff M, Neisius U, Ikoma A, Fartasch M, Heyer G, Skov PS, Lugaer TA, Schmelz M (2003) Proteinase-activated receptor-2 mediates itch: a novel pathway for pruritus in human skin. J Neurosci 23:6176-6180.

Steinhoff M, Bienenstock J, Schmelz M, Maurer M, Wei E, Biro T (2006) Neurophysiological, neuroimmunological, and neuroendocrine basis of pruritus. J Invest Dermatol 126:1705-1718.

Tuckett RP (1982) Itch evoked by electrical stimulation of the skin. J Invest Dermatol 79:368-373.

Tuckett RP, Wei JY (1987) Response to an itch-producing substance in cat. II. Cutaneous receptor populations with unmyelinated axons. Brain Res 413:95-103.

Wahlgren CF (1999) Itch and atopic dermatitis: an overview. J Dermatol 26:770-779.

Wei JY, Tuckett RP (1991) Responses of cat ventrolateral spinal axons to an itch-producing stimulus (cowhage). Somatosens Mot Res 8:227-239.

White JC and Sweet WH (1969) Pain and the neurosurgeon. Springfield, IL: Charles C. Thomas.

Yosipovitch G, Greaves MW, Schmelz M (2003) Itch. Lancet 361:690-694.

Zhang X, Wenk HN, Gokin AP, Honda CN, Giesler Jr GJ (1999) Physiological studies of spinohypothalamic tract neurons in the lumbar enlargement of monkeys. J Neurophysiol 82:1054-1058. 